\title{
Cerebral Venous Thrombosis and Polycythemia: a Potential Pitfall
}

\author{
Alexandre Perez-Girbes, Pierre Lemercier, Carlos Leiva-Salinas
}

Keywords: cerebrovascular disease, magnetic resonance imaging, neuroimaging

doi:10.1017/cjn.2016.20

Can J Neurol Sci. 2016; 43: 845-846

\section{CASE Report}

A 42 year-old-man, with history of Eisenmenger's syndrome presented to the Emergency Department (ED) with headache and bilateral hand paresthesia. The patient's hematocrit was noted to be $75.3 \%$ and the hemoglobin was $24.7 \mathrm{~g} / \mathrm{dl}$.

A non-enhanced brain computed tomogram (CT) showed hyperdense venous sinuses and cortical veins. A region of interest (ROI) placed in the superior sagittal sinus measured 65 Hounsfield Unit (HU) (Figure 1) and the Hounsfield unit-tohematocrit ratio ( $\mathrm{H}: \mathrm{H}$ ratio) was 0.86 . The patient had a history of an anaphylactic reaction to iodinated contrast agent, thus a magnetic resonance imaging scan (MRI) with contrast was performed to rule out cerebral venous thrombosis (CVT). Contrastenhanced MRI venography (Figure 2) did not show filling defects in the dural venous sinuses nor in the major vessels of the deep cerebral venous system.

\section{DiscuSSION}

"Hemoconcentration" or elevated levels of hemoglobin or hematocrit increase $\mathrm{x}$-ray attenuation within the brain vasculature $^{1}$. Features of polycythemia on non-enhanced brain CT scan includes increased attenuation of the dural venous sinuses and cortical and deep cerebral veins and may simulate an acute CVT. Cerebral venous thrombosis is a known complication of polycythemia and hence they may coexist. Recently, Garetier et $\mathrm{al}^{2}$ re-evaluated the value of spontaneous hyperdensity in the venous sinus on non-contrast $\mathrm{CT}$ and reported a cut-off value of $70 \mathrm{HU}$ to distinguish between normal sinuses and CVT.

In addition to the absolute density measurement, Black et al ${ }^{1}$ recently introduced the $\mathrm{H}: \mathrm{H}$ ratio as a normalized index blood attenuation with regard to hemoconcentration. They reported a mean $\mathrm{H}: \mathrm{H}$ ratio of 2.20 and 1.44 in patients with and without CVT, respectively.

Buyck et al. ${ }^{3}$ proposed the routine calculation of the $\mathrm{H}: \mathrm{H}$ ratio to increase the sensitivity of non-contrast CT of the brain in the diagnosis of CVT. Their results showed an optimal threshold of 1.52 , leading to a sensitivity of $95 \%$, specificity of $100 \%$, and accuracy of $97.5 \%$.

In our case, the superior sagittal sinus had a mean density of $65 \mathrm{HU}$ and a $\mathrm{H}: \mathrm{H}$ ratio of 0.86 . According to aforementioned values, the patient had a very low likelihood of CVT, as confirmed by MRI. ${ }^{4}$

As a summary, in patients with polycythemia and neurological symptoms, CT or MRI venography may be necessary to definitively rule out CVT. However, the use of absolute density

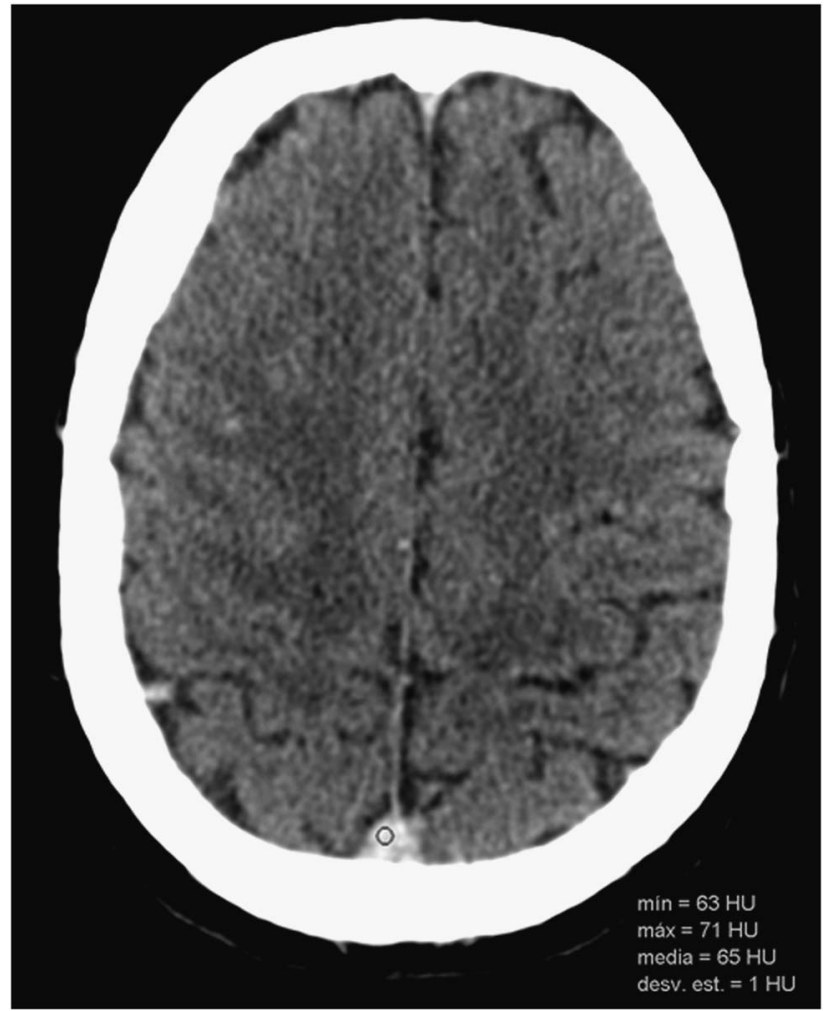

Figure 1: Axial image from a non-contrast CT of the head shows hyperdense superior sagittal sinus and cortical veins (ROI measured 65 HU on the superior sagittal sinus).

measurements in the venous sinus and, more specially, the calculation of the $\mathrm{H}: \mathrm{H}$ ratio, may be helpful in the imaging workup of the patient with clinical suspicion of CVT in the ED setting, particularly in patients with polycythemia.

\section{Disclosures}

Alexandre Perez-Girbes, Pierre Lemercier, and Carlos LeivaSalinas do not have anything to disclose.

From the Radiology Department (AP-G, PL), HUP La Fe, Valencia, Spain; Department of Radiology (CL-S), University of Missouri, Columbia, MO, USA.

Received January 1, 2015. Final Revisions Submitted January 9, 2016. Date OF ACCEPTANCE JANUARY 20, 2016.

Correspondence to: Alexandre Perez-Girbes, HUP La Fe - Radiology Department, Av. Fernando Abril Martorell, 106 Valencia Valencia, Spain. Email: aperezgirbes@gmail.com 

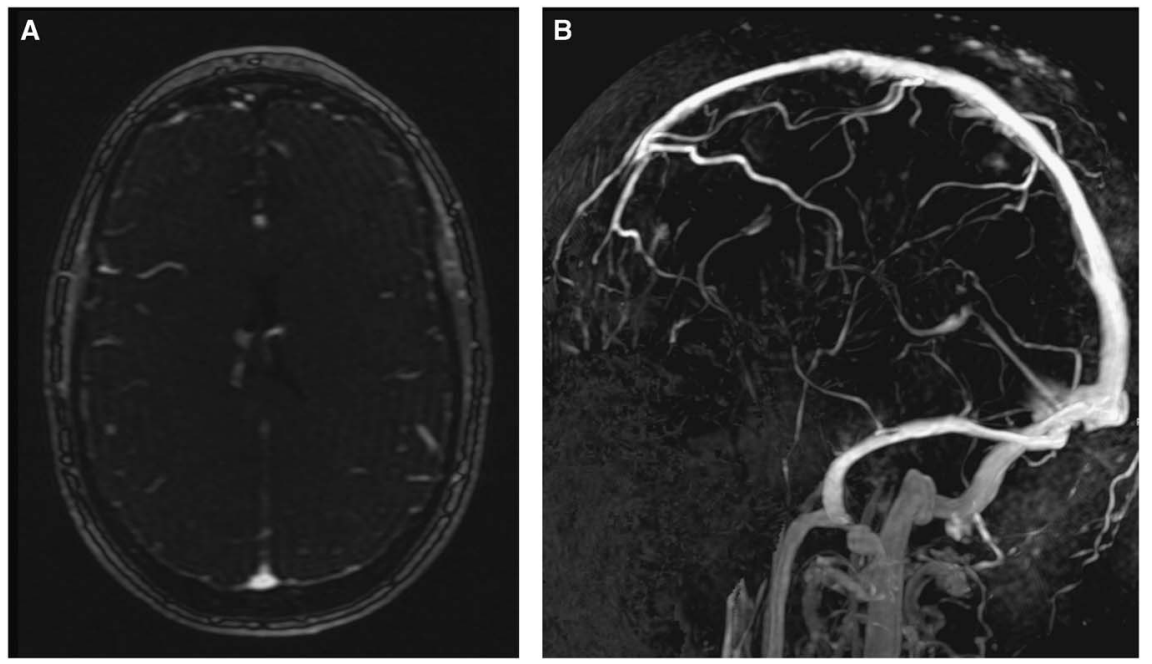

Figure 2: Axial image from contrast-enhanced MRI venography $(A)$ and $3 D$ reformation $(B)$ showed no filling defects in the superior sagittal sinus or in the major vessels of the deep cerebral venous system.

\section{REFERENCES}

1. Black DF, Rad AE, Gray LA, Campeau NG, Kallmes DF. Cerebral venous sinus density on noncontrast CT correlates with hematocrit. AJNR Am J Neuroradiol. 2011;32:1354-1357.

2. Garetier M, Rousset J, Pearson E et al. Value of spontaneous hyperdensity of cerebral venous thrombosis on helical CT. Acta Radiol. 2014;55:1245-52.
3. Buyck PJ, De Keyzer F, Vanneste D, Wilms G, Thijs V, Demaerel P. $\mathrm{CT}$ density measurement and $\mathrm{H}: \mathrm{H}$ ratio are useful in diagnosing acute cerebral venous sinus thrombosis. AJNR Am Neuroradiol. 2013;34:1568-72.

4. Leach JL, Wolujewicz M, Strub WM. Partially Recanalized Chronic Dural Sinus Thrombosis: Findings on MR Imaging, Time-ofFlight MR Venography, and Contrast-Enhanced MR Venography. AJNR Am J Neuroradiol. 2007;28:782-9. 